\author{
Tomasz Kołodziej* \\ University of Zielona Góra, Zielona Góra, Poland \\ https://orcid.org/0000-0003-1358-0270
}

\title{
The influence of players' nationality on the effectiveness of eSports teams based on the example of The International DOTA 2 tournaments
}

\section{Introduction}

The dynamic development of electronic sports, also called eSports, took place at the beginning of the new millennium, but the leagues for players were established in the early 1980s. At that time, and for almost the entire 1990s, the market for games and tournaments played between players had been developing. However, it was only the universal access to the Internet that initiated the era of online games, which gave the possibility of competition to players from all over the world and initiated a new stage of development of eSports (Dąbrowski, 2011). Currently, the popularity of eSports is so high that there are more and more voices that it should appear as an Olympic discipline (Gries, 2019). The term eSports appeared for the first time in the late 1990s, and one of the first sources in which it was used is Matt Bettington's statement from 1999 for Online Gamers Association, in which he compared eSports to traditional sports. At the same time, he predicted that soon eSports tournaments will be broadcast on television (Verhoeff, 2019). The dynamics of eSports development is best illustrated by the valuation of this market. In 2017, it amounted to \$655 million and increased to over \$1 billion in 2019. The forecasts assume that in 2022 this market will be worth almost $\$ 1.8$ billion (Newzoo, 2019). The popularity of eSports has contributed to the growing interest of sponsors and the increasing professionalism of the teams. In the initial phase of the creation of the eSports scene, the possibilities of electronic games were limited, for technical reasons, to small groups of players. As a result, the first teams were usually homogeneous in a natural way. The spread of broadband Internet access enabled players to play against opponents from all over the world and, at the same time, create truly multinational teams. Therefore, the Internet abolished one of the main barriers to the development of eSports - the geographical barrier. Progressive professionalization, increasing awards and sponsorship enabled teams to contract the best players on the same terms as in traditional sport, e.g. football. These processes have enabled the development of pro-

\footnotetext{
* Correspondence address: Instytut Socjologii, Al. Wojska Polskiego 69, 65-762 Zielona Góra, Polska, e-mail: t.kolodziej@is.uz.zgora.pl.
} 
fessional, multinational eSports teams. Similarly to traditional sport, professional teams try to attract the best possible players, also from abroad, which is supposed to raise the level of the team and promote success.

The main purpose of the presented paper is to verify the hypothesis about the existence of a relationship between the national diversity of members of eSports teams in DOTA 2 and the results achieved by these teams. DOTA 2 is the first game in which more than one million people played simultaneously on the online platform and it is one of the most popular eSports competitions. The latest tournament in The International series, which is considered the most prestigious, attracted more than 55 million viewers from around the world, with a prize pool of more than $\$ 25$ million (Esports Charts, 2019).

For the purpose of the paper, the hypothesis was formulated as follows: teams whose members represent different nationalities achieve higher efficiency and higher positions in DOTA 2 international tournaments than teams of uniform nationalities.

\section{Is eSports a sport?}

The discussion about whether eSports is a real sport and can be put in one row with e.g. football, basketball, long jump or javelin throw has been taking place since its creation. Reflections on the definition of eSports appear in the works of Michael Wagner, Andrzej Stępnik, Juho Hamari and Max Sjöblom, Seth E. Jenny et al. or Anthony Pizzo et al. (Wagner, 2006; Stępnik, 2009; Hamari, Sjöblom, 2017; Jenny et al., 2017; Pizzo et al, 2018). There is no generally agreed and accepted definition of what eSports is. The main doubts relate to whether eSports has the characteristics of a traditionally understood sport. This is all the more difficult as individual authors refer in their works to different definitions of traditional sport. At the level of Polish academic work, Stępnik's analyses seem to be particularly interesting as he refers to the theory of sport and the definition of sport by Maciej Demel. In this definition, there are seven conditions that are both necessary and sufficient for a given activity to be considered a sport:

1. independence of direct motives from basic life needs;

2. positive emotions accompanying decisions and actions;

3. lack of material effect, which is always the result of production work;

4. motor character of the activity with a specialist accent;

5. regularity in striving to achieve maximum results;

6. bright moment of competition as one of the basic stimuli for improvement;

7. strict adherence to the rules governing equipment standards, conditions and forms of operation, which enable the results to be measurable and comparable.

He demonstrates in his work that eSports meets all these criteria, so according to this definition it should be considered a sport (Stępnik, 2009: 216).

Referring to foreign studies, it is worth mentioning the work of Jenny who together with his team carried out analyses similar to those of Stępnik (Jenny et al., 2017). In 
their analyses, referring to Allen Guttman's concept and Bernard Suits (Guttman, 1978; Suits, 2007), they distinguished the following constitutive features of sport:

1. takes into account a game that is voluntary and results from internal motivation;

2. it is organized according to specific rules;

3. takes into account the competition in which the winner and defeated are the ones;

4. requires specific skills that are the result of exercise and training;

5. requires the involvement of the physical skills and capabilities of the player's body;

6. is not the result of temporary fashion and has a wide range of occurrence;

7. social institutions have been developed which are the guardians of compliance with the applicable rules.

The authors indicate that eSports generally meets all these criteria and, like Stępnik, believe that eSports should be considered a sport in the traditional sense of the word (Jenny et al., 2017: 5-15). In both works, one of the basic doubts is the question of physical effort and body involvement in traditional sports and computer games, in which it would be much smaller. Meanwhile, as Stępnik points out, a similar accusation can be formulated in relation to chess, which nobody denies to be called a sport (Stępnik, 2009: 3). At the same time, the training of a professional eSporter often includes such elements as gym training, running, proper diet, working with a psychologist (Kuźbik, 2018).

Therefore, assuming that eSports can be treated as a type of sport in the traditional sense, the question should be asked about its characteristics. It is not a homogeneous category, but there are many different games within the eSports area, as well as many different sports falling within the traditional sport category. The most popular games in the eSports scene include StarCraft II, FIFA Online 3, League of Legends, DOTA2 and Counter-Strike: Global Offensive (Pizzo et al., 2018). The essence of eSports is, therefore, competitions in computer games, which most often take the form of organized, professional tournaments (Jenny et al., 2017). The two most popular types of games in which players compete against each other in tournaments are sports games and real-time strategy games (RTS). The first of these types are games simulating traditional sports (e.g. FIFA Online 3 simulating football games). In RTS games such as DOTA 2 or Leaque of Legends, players most often create competing teams that try to defeat their opponents on the battlefield (Pizzo et al., 2018). This article concerns players participating in DOTA 2 tournaments, which represents the latter type of a tournament.

\section{Nationality diversity}

The role of nationality and national diversity of sports teams in their effectiveness was the subject of numerous analyses. Reference should be made to the texts by Andrea Prat, Leif Brandes, Egon Franck and Philipp Theiler, Franck and Stephan Nüesch, Leo Kahane, Neil Longley and Robert Simmons, Keith Ingersoll, Edmund Malesky and Sebastian Saiegh (Prat, 2002; Brandes, Pranck, Theiler, 2009; Franck, Nüesch, 2010; Kahane, 
Longley, Simmons, 2013; Ingersoll, Malesky, Saiegh, 2014). Sports teams are an interesting subject of rwesearch in the context of the impact of national diversity on their effectiveness. The clear structure, membership rules and public character of the teams make it easier to access data on their members. At the same time, players in these teams often have similar demographic characteristics such as gender and age. The findings so far do not allow an unambiguous assessment of whether the effectiveness of sports teams is better fostered by hetero- or homogeneity of the nationality of players. The very concept of the nationality of players should be clarified here. This concept, translated and used after English speaking authors, may create terminological problems in the Polish context. In the presented paper, the understanding of this notion results directly from the nature of available data. The nationality of players is determined by objective factors of a formal and legal nature (Barwiński, 2004: 8-9), i.e. having the status of a citizen of a given country, which is expressed, for instance, by possessing relevant documents.

The results of Prat's analysis indicate that which model of organization turns out to be better depends to a large extent on what kind of decisions have to be made. He notes that teams of different nationalities will be better at solving problems and tasks that require creativity and unconventional thinking. In the meantime, homogeneous national teams may achieve better results in the case of tasks of a more stable and schematic character. The findings of Franck, Brandes and Theiler suggest that representatives of different nationalities may have some unique skills resulting from their specific backgrounds. These characteristics and skills related to nationality may be relevant for the performance of specific tasks in a team. The authors' analyses show that players of specific nationalities perform better in specific roles in a team. In this way the team manager can, by skillfully involving representatives of different nationalities, broaden the range of possibilities and skills of the team (Brandes, Franck, Theiler, 2009: 240). The findings seem to be confirmed by the results presented by Kahane, Longley and Simmons. They showed in their publication that the presence of players of different nationalities in the team broadens the scope of possibilities of the whole team in relation to the situation in which it would consist of the only domestic players. At the same time, they noted that foreign players can have a higher level of skills than domestic players, which in turn can benefit the team by stimulating competition and motivating existing players to improve their skills (Parshakov, Zavertiaeva, 2015).

There are significantly fewer analyses concerning the eSports teams which are characterized by a similar specificity as traditional sports teams. This includes the work of Petr Parshakov and Marina Zavertiaeva and Parshakov, Dennis Coates and Zavertiaeva. The analyses presented by the authors confirm that the diversity of nationalities of the team members may be important for the effectiveness and results achieved by the team. These analyses show that the diversity of nationalities of the teams may result in increased effectiveness and bring benefits in the long-term perspective of the team's functioning. At the same time, they point out that in eSports teams the importance of trainers is less important for the results achieved than in traditional sports. Moreover, 
due to the relatively short history of eSports development, most coaches are former or current players whose age is close to the age of the players. Many teams, also playing in the most important professional tournaments, do not have coaches at all. At the same time, the authors point out that these results do not allow to decide which of the models is more effective and indicate the need for further research in this area (Parshakov, Zaveriaeva, 2015; Parshakov, Coates, Zavertiaeva, 2018).

The language barrier is also an important problem from the point of view of the players' national diversity. Effective functioning of multinational eSports teams more than in traditional sport depends on the ability of players to communicate effectively. The language barrier effectively prevents efficient team cooperation. At present, the basic competence of professional eSports players is the knowledge of English. On the one hand, it is a requirement imposed by the creators of games in which English is the basic language, and on the other hand, this language is the basic language of communication between the players themselves (Nyćkowiak, Kołodziej, 2018).

\section{The specificity of DOTA 2 teams and tournaments}

DOTA 2 is a game from the subgenre Multiplayer Online Battle Arena (MOBA). Two teams of five players take part in the game and their task is to defeat the opponent by capturing their base and destroying their main building (Semenov et al., 2016: 26-27). Games of this kind require players to master very complex systems and strategies, sophisticated mechanics, which the game is based on, and the ability to teamwork and cooperation with the team (Georgen, 2015). In the game, each player controls one character, the so-called hero, who has a specific set of individual skills and characteristics that can be developed in the course of the game, and the direction of this development is crucial for the effectiveness and usefulness of the hero in the game. Players choose ${ }^{1}$ one hero from one hundred and seventeen available, which are divided into ten classes representing the function that the hero performs on the board. However, the choice of the character is not completely free and depends on the role of the player in the team, the strategy of the team and the heroes chosen by the other members. At the same time, the team must take into account the choices made by the players of the opposing team. As a result, the selection of characters by the team is a complicated process and each member of the team must have the ability to play with many heroes and master different strategies of their development and use. The professionalization of players and the time needed to master the game with particular heroes has led to a gradual specialization of players in fulfilling certain functions in the team and playing the characters of selected classes.

The specificity of professional teams taking part in the most important tournaments results also from the characteristics of the players themselves. All of them are men at a young age, which means that the only thing that significantly differentiates them is their

1 The freedom of choice depends on the type of play and the rules of the tournament, which may vary from one game to another. 
nationality. This specificity makes these teams even more similar to the teams present in traditional sports such as football or basketball.

The series of The International tournaments began as an annual championships in 2011 and have remained the most important, largest and most prestigious tournaments of DOTA 2 to this day. The tournaments are held in two stages. The first stage is a phase in which teams are divided into two groups in which the eliminations to the main part of the tournament are played. The main phase of the tournament is the cup phase and takes place in two ladders. The upper part of the tournament offers teams a shorter route, understood as less games that have to be played in order to reach the final. In this ladder, the teams which in the group phase will take leading positions in their groups are set up. Other teams are placed in the bottom ladder and can also play in the finals, but in order to achieve this they have to play more games. Each match, depending on the tournament and its phase, consists of two or three matches. The total number of matches and battles that a team must play in order to play in the final depends on its effectiveness in each subsequent match, both in the group phase and in the main phase of the tournament.

\section{Data}

The analysis presented in the article includes all teams taking part in eight tournaments of The International series 2011-2018. These are all tournaments of this series played in these years. The analysis, therefore, covers the entire team population and includes all players participating in the tournaments under analysis. The data used comes from a database created within the framework of a proprietary project carried out by Justyna Nyćkowiak, PhD and Tomasz Kołodziej, PhD from the Institute of Sociology at the University of Zielona Góra. In order to create the database, Internet sources were used to provide official statistics on the results of individual matches and players. All the information used to complete the database was cross-checked in various sources, which was an element aimed at ensuring their validity. The database included such data as: team name, name, surname, year of birth, year of start of the player's career, roles played in the team, results achieved by the team in the analyzed tournaments and the amount of prizes received. The data includes one hundred and thirty-two teams with six hundred and sixty players who played two thousand four hundred and thirty-seven games. Eighteen teams competed in the last two tournaments of The International series, while sixteen teams competed in the previous tournaments of the series. Some teams competed in several of the analyzed tournaments, but due to significant changes in the composition of the teams between the tournaments, they can be treated as separate cases each time, because a change in the composition of the team can significantly affect the style and level of play of the team (Parshakov, Coates, Zavertiaeva, 2018: 5065).

The data included in the analyses comprise the following information: 
1. Nationality of players - on the basis of this data, the level of national homogeneity of teams was determined. It should be noted that each team always consisted of five players. For the teams analyzed, there could be representatives of one, two, three, four or five different nationalities.

2. Team effectiveness - this coefficient is calculated as the ratio of the victories of the team in a given tournament to the total number of matches played in that tournament. In its basic form, efficiency is expressed as a percentage, so it can be used for comparison, no matter how many battles a team has played in a given tournament. In the analysis, this factor was converted into a numerical form with values from 0 to 1 .

3. Position taken in a tournament - a variable concerning the place that a given team took in the final classification of a given tournament.

\section{National diversity of teams}

In each of the analyzed tournaments from 80 to 90 players took part. The data presented in Chart 1 relate to the number of represented by players, nationalities in each tournament. The presented data confirm the increase in the number of nationalities represented by players in subsequent competitions. It should be noted that this increase is relatively stable. It seems that this may be a process related to the growing popularity and availability of eSports. According to estimates, the number of players has increased from 1.8 billion in 2014 to 2.4 billion in 2018 and is expected to reach 2.7 billion in 2021 (per Statista).

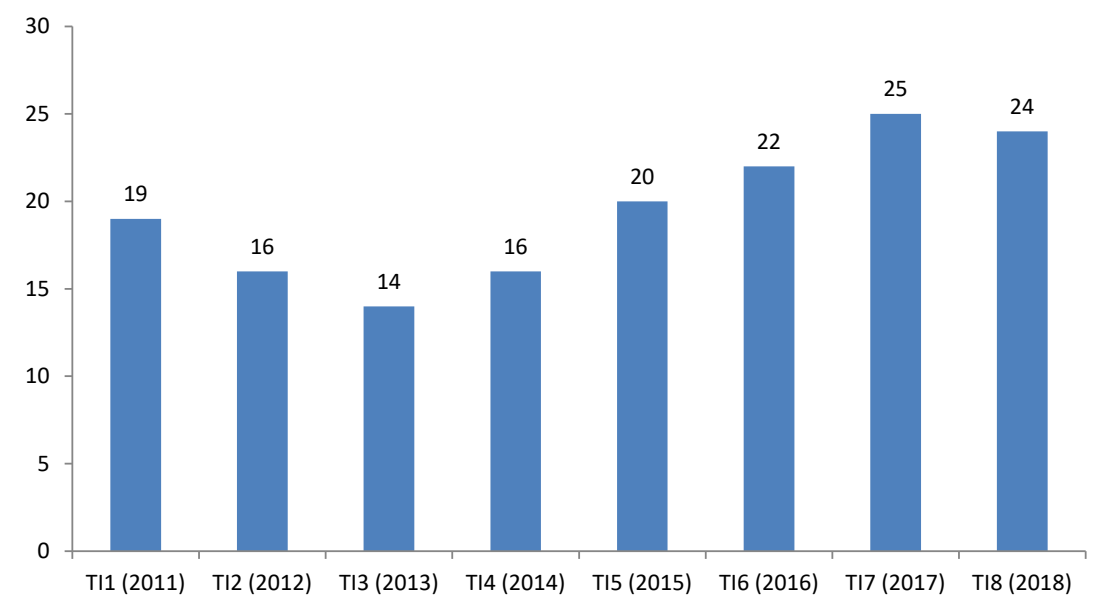

Chart 1. Number of nationalities represented in subsequent The International series tournaments

(\%), TI - The International Source: own elaboration. 
Thirty-six nationalities took part in all analyzed tournaments. The percentage share of representatives of particular nationalities is presented in Table 1. The data allow us to say that the players are definitely dominated by representatives of the Asian continent. Chinese players account for nearly one third of all tournament participants and the ten most represented nations account for almost $79 \%$ of all tournament participants. At the same time, such a large number of nationalities and the presence of even individual cases representing individual countries show how internally diverse teams can be analyzed in this aspect.

Table 1. Percentage share of nationality representatives in total number of players (\%)

\begin{tabular}{|l|l|l|l|l|l|l|l|l|}
\hline No. & $\begin{array}{c}\text { Name } \\
\text { of the country }\end{array}$ & \% & No. & $\begin{array}{c}\text { Name } \\
\text { of the country }\end{array}$ & \% & No. & $\begin{array}{c}\text { Name } \\
\text { of the country }\end{array}$ & \% \\
\hline 1 & China & 27.9 & 13 & Australia & 1.5 & 25 & Bulgaria & 0.5 \\
\hline 2 & Malaysia & 8.3 & 14 & Finland & 1.5 & 26 & Czech Republic & 0.5 \\
\hline 3 & USA & 7.1 & 15 & France & 1.4 & 27 & Netherlands & 0.5 \\
\hline 4 & Russia & 6.2 & 16 & Estonia & 1.2 & 28 & Belarus & 0.3 \\
\hline 5 & Ukraine & 6.2 & 17 & Israel & 1.2 & 29 & Croatia & 0.3 \\
\hline 6 & Sweden & 5.8 & 18 & Macau & 1.2 & 30 & Lebanon & 0.3 \\
\hline 7 & Philippines & 4.4 & 19 & Thailand & 0.9 & 31 & Slovakia & 0.3 \\
\hline 8 & Canada & 4.2 & 20 & Jordan & 0.8 & 32 & Bosnia and & 0.2 \\
\hline 9 & Denmark & 4.2 & 21 & Pakistan & 0.8 & 33 & Greece & 0.2 \\
\hline 10 & Germany & 4.2 & 22 & Peru & 0.8 & 34 & Macedonia & 0.2 \\
\hline 11 & Singapore & 2.7 & 23 & Romania & 0.8 & 35 & Mexico & 0.2 \\
\hline 12 & South Korea & 2.6 & 24 & Brazil & 0.6 & 36 & Serbia & 0.2 \\
\hline
\end{tabular}

Source: own elaboration.

Each team participating in DOTA 2 tournaments must consist of five players. There may, therefore, be a situation where all players of the same nationality are in a team and the team is homogeneous, but the team may also be of different nationalities. The data concerning national diversity of teams taking part in the analyzed tournaments are presented in the Chart 2 . The presented data allow to distinguish three main types of teams. The first type is homogeneous teams with players representing only one nationality. The second type is a team where there are players representing two nationalities. The third type is the most diverse in terms of the number of nationalities represented. There are at least three different nationalities in these teams. These three types are present in the analyzed population with the same frequency. At the same time, it should be noted that heterogeneous teams with representatives of at least two nationalities constitute over $67 \%$ of the total analyzed population. In the analysis of the effectiveness of individual teams, three types of teams will be used. 
The above findings suggest that it is common for teams to have players of different nationalities in the same team. However, it should be taken into account that the analyzed tournaments were played over a period of almost eight years. It can, therefore, be assumed that the presence of multinational teams was of varying intensity during this period. The data concerning the number of these teams in subsequent tournaments are presented in Chart 3.

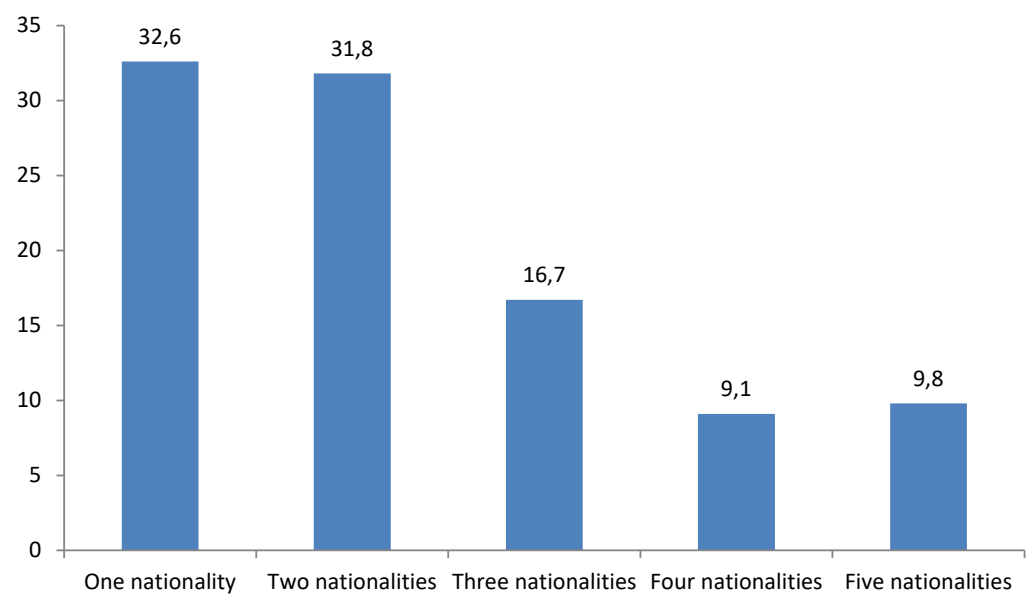

Chart 2. Nationalities of the teams (\%) Source: own elaboration.

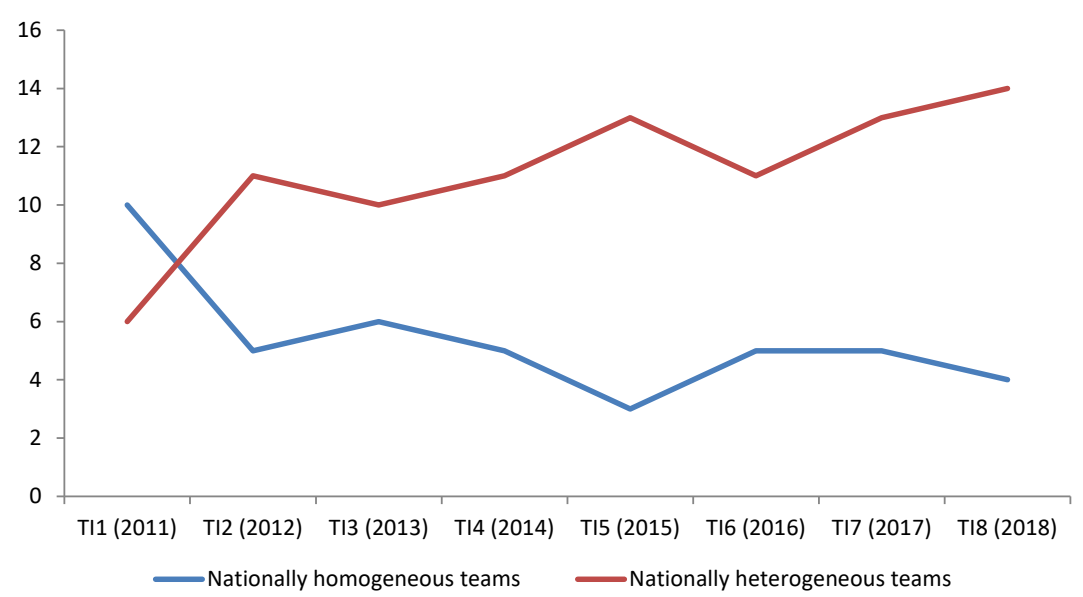

Chart 3. National diversity of teams in 2011-2018 (N) Source: own elaboration. 
The data presented in Chart 3 show that only in the initial period, i.e. the first tournament of The International series, the number of homogeneous teams was higher than that of multinational teams. In the following tournaments of this series, the disproportion increased to the benefit of the second model of team organization. There is a clear trend indicating a gradual decrease in the number of homogeneous teams. Referring to the findings of Parshakov, Coates and Zavertiaeva, as well as Kahane, Longley and Simmons and Franck, Brandes and Theiler, it can be assumed that multinational teams, by using the specific skills of their players, prevent homogeneous teams from being promoted to the group stage of The International series tournaments and this is also the reason for the decrease in the number of these teams in the tournaments.

The presented analyses clearly indicate the direction of changes that took place in the case of teams participating in The International tournaments. The initial domination of the national teams has been replaced by a multinational model. In 2018, of the eighteen teams in the tournament, only four were homogeneous. It seems that overcoming geographical and linguistic barriers has made the model of multinational professional teams increasingly popular. At the same time, it should be noted that the creation of such teams is also possible thanks to higher and higher prizes for winning the tournament. In 2011, in the first tournament of The International, the prize pool was \$1.6 million, and in 2018 it increased to $\$ 25.5$ million.

\section{Efficiency of teams}

The effectiveness of teams measured as the ratio of winnings to the total number of games played allows the best possible assessment of how effectively a team copes with the competition. It should be assumed that the basic strategy of all teams is to win each subsequent game. This assumption is based on the fact that it is the only strategy that gives certainty of winning the tournament and, at the same time, shortens the route to it as much as possible. The importance of this is illustrated by the differences in the number of games needed to be played. Assuming that Team A won the tournament without losing in any of the battles, the victory was achieved after twelve games in which they played twenty-five battles. If the same team had achieved victory with as many individual battles as possible in order to win the tournament, it would have had to play fifteen matches and a total of thirty-seven games to win the tournament. The difference shows how a successful game in each subsequent match shortens the way to the final victory in the tournament.

The created factor shows the efficiency on the scale in the range from 0 to 1 , where a score of 0.5 means the same number of victories as defeats. The coefficient variable is a quantitative variable with a normal distribution. The coefficient for the purposes of analysis was recoded into four categories corresponding to the following ranges: 0-25\% of wins, $26-50 \%$ of wins, $51-75 \%$ of wins and $76-100 \%$ of wins. This division was dic- 
tated by the need to take into account the levels of efficiency that enable effective fight for top positions in tournaments. Although a high level of efficiency does not guarantee victory in a tournament, it is a necessary condition to compete for victory.

Table 2 shows the results of the comparison of the performance ratio achieved by the three types of team.

Table 2. Value of the coefficient of performance for teams (\%)

\begin{tabular}{|l|c|c|c|c|}
\hline & \multicolumn{4}{|c|}{ Team efficiency } \\
\hline & $0-0.25$ & $0.26-0.5$ & $0.51-0.75$ & $0.76-1$ \\
\hline Nationally homogeneous teams & 23.3 & 39.5 & 34.9 & 2.3 \\
\hline Two-nationality teams & 11.9 & 47.6 & 35.7 & 4.8 \\
\hline Multinational teams & 12.8 & 42.6 & 36.2 & 8.5 \\
\hline
\end{tabular}

Source: own elaboration.

The data in Table 2 indicate that more nationally diverse teams, more often than homogeneous teams, achieve the highest range of the coefficient of effectiveness. Teams in which players represented two nationalities twice as often, and teams more diverse almost four times more often than homogeneous teams, were able to win more than threequarters of all matches. What is equally important, these teams almost twice as rarely have the lowest efficiency, which means that they win in no more than every fourth match. It seems that these differences clearly indicate higher effectiveness achieved by multinational teams. At the same time, these results allow us to assume that teams of more diverse nationalities will more often achieve top positions in the analyzed tournaments. Chart 4 also shows that there is a positive correlation between these variables. The spread of points clearly confirms that only teams with an efficiency of at least $60 \%$ achieved victory in tournaments. The lowest efficiency that allowed to be ranked in the top three in the overall tournament classification in the tournament was $50 \%$, but most often it was necessary to win more than half of the games to be ranked. At the same time, it should be noted that achieving an efficiency of 0.76 guaranteed a place in the top three teams in the general classification of the tournament.

The correlation (Rho-Spearman) between the coefficient of efficiency and the places occupied by the teams is statistically significant and amounts to 0.802 . This result confirms a strong relationship between the efficiency and the final result achieved by the teams.

The comparison of the distinguished types of teams with the places that these teams occupied in tournaments is presented in Table 3 and does not give such unambiguous results. Although teams whose players represented three or more nationalities were in the top positions most often, the difference between these teams and the teams of the same nationality is less than $5 \%$. However, the data presented here allow us to notice 


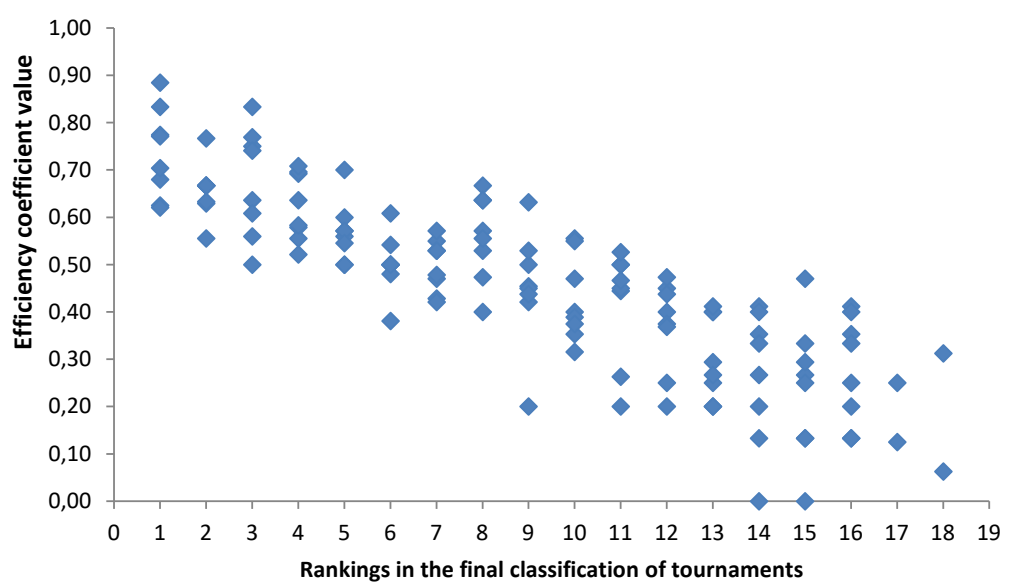

Chart 4. Spread chart for the variables: coefficient of performance and place in the final classification of the tournament Source: own elaboration.

that the lowest number of multinational teams took positions at the end of tournament classifications. It is also visible that multinational teams more often than other teams achieve places in the top ten of the tournament final classification.

Table 3. Ranks achieved by the teams in the tournaments

\begin{tabular}{|l|c|c|c|}
\hline & \multicolumn{3}{|c|}{ Ranks achieved in the tournaments } \\
\hline & $1-3$ & $4-10$ & $11-18$ \\
\hline Nationally homogeneous teams & 18.6 & 39.5 & 41.9 \\
\hline Two-nationality teams & 11.9 & 40.5 & 47.6 \\
\hline Multinational teams & 23.4 & 46.8 & 29.8 \\
\hline
\end{tabular}

Source: own elaboration.

\section{Conclusions}

The main aim of the presented article was to verify the hypothesis concerning the relationship between the national diversity of professional eSports teams taking part in DOTA 2 games and the results achieved by these teams. The analysis included the entire population of teams taking part in eight The International series tournaments, which took place in the years 2011-2018. The data on the nationality of players in these teams, the number of games played by the teams and the number of victories achieved, as well as the places which the teams occupied in the general classifications of the analyzed 
tournaments were used. On the basis of the conducted analyses, the following conclusions can be presented.

Firstly, the number of multinational teams in The International series tournaments increased in the analyzed period. It seems that with the professionalism, development of eSports and growing prizes, more and more teams are willing to reach for foreign players, which may improve their level of playing and increase their chances to fight for top positions in tournaments. At the same time, it should be noted that the number of home-grown teams is decreasing.

Secondly, the efficiency of teams where players represent at least three nationalities is significantly higher than that of other teams. Multinational teams have a higher victory rate and can, therefore, compete more effectively for the highest positions in tournaments. The correlation between team efficiency and tournament position is statistically significant and takes the value of 0.802 , which gives a strong basis for the assumption that teams with a high coefficient of performance will have high positions in tournaments.

Finally, the teams in which players represent at least three nationalities, more often than other teams, took high positions in the analyzed tournaments.

On the basis of the results obtained, it is possible to confirm the hypothesis. At the same time, it should be noted that these results refer only to the population of teams participating in a specific tournament series. They cannot be generalized not only to all eSports teams in different games, but also to all teams participating in all DOTA 2 tournaments. However, these results form the basis for hypotheses and show the need for further analysis of the impact of the nationality of players on the performance of professional eSports teams.

\section{Bibliography}

Barwiński M. (2014), Pojęcie narodu oraz mniejszości narodowej i etnicznej w kontekście geograficznym, politycznym i socjologicznym, "Acta Universitatis Lodziensis. Folia Geographica Socio-Oeconomica", No. 5, pp. 59-74.

Brandes L., Franck E., Theiler P. (2009), The effect from national diversity on team production Empirical evidence from the sports industry, "Schmalenbach Business Review", No. 61(2), pp. 225-246, DOI: https://doi.org/10.1007/BF03396785.

Dąbrowski A. (2011), E-sport - przydawka czy coś więcej?, [in:] Społeczne zmagania ze sportem, edit. Ł. Rogowski, R. Skrobacki, Poznań, pp. 117-140.

Esports Charts (2019), https://escharts.com/tournaments/dota2/international-2018 [access on: 20.05.2019].

Franck E., Nüesch S. (2010), The effect of talent disparity on team productivity in soccer, "Journal of Economic Psychology", No. 31(2), pp. 218-229, DOI: https://doi.org/10.1016/j. joep.2009.12.003.

Georgen C. (2015), Well Played \& Well Watched: DOTA 2, Spectatorship and eSports, "Well Played: A Journal on Video Games, Values, and Meaning", No. 4(1), p. 179, DOI: https://doi. org/10.1184/R1/6687020.

Gries S. (2019), eSports and the Olympic Movement: A Short Analysis of the IOC eSports Forum, 
[in:] eSports Yearbook 2017/18, edit. J. Hiltscher, T. M. Scholz, https://esportsyearbook.com/ eyb201718.pdf [access on: 25.06.2019].

Guttmann A. (1978), From ritual to record: The nature of modern sports, New York.

Hamari, J., Sjöblom M. (2017), What is eSports and why do people watch it?, "Internet research", No. 27(2), pp. 211-232, DOI: https://doi.org/10.1108/IntR-04-2016-0085.

Ingersoll K., Malesky E.J., Saiegh S.M. (2014), Diversity and Group Performance: Evidence from the World's Top Soccer League, [in:] APSA 2014 Annual Meeting Paper, DOI: https://doi.org/ 10.1080/00036846.2018.1470315.

Jenny S.E., Manning R.D., Keiperc M.C., Olrichd T.W. (2017), Virtual(ly) athletes: where eSports fit within the definition of "Sport", "Quest", No. 69(1), pp. 1-18, DOI: https://doi.org/10.1080 /00336297.2016.1144517.

Kahane L., Longley N., Simmons R. (2013), The effects of coworker heterogeneity on firm-level output: assessing the impacts of cultural and language diversity in the National Hockey League, "Review of Economics and Statistics", No. 95(1), pp. 302-314, DOI: https://doi.org/10.1162/ REST_a_00221.

Kuźbik P. (2018), E-sport jako kreator nowych warunków organizacyjnych w zmiennym i dynamicznym otoczeniu, "Ekonomiczne Problemy Usług", No. 131(2/1), pp. 211-220, DOI: https:// doi.org/10.15611/pn.2016.430.19.

Newzoo (2019), https://newzoo.com/solutions/standard/market-forecasts/global-esports-market-report/ [access on: 23.06.2019].

Nyćkowiak J., Kołodziej T. (2018), Zróżnicowanie narodowościowe zespołów e-sportowych, [in:] Transgraniczność w perspektywie socjologicznej. Europa - podzielona wspólnota?, edit. M. Zielińska, D. Szaban, B. Trzop, Zielona Góra, p. 211.

Parshakov P., Coates D., Zavertiaeva M. (2018), Is diversity good or bad? Evidence from eSports teams analysis, "Applied Economics", No. 50(47), pp. 5064-5075, DOI: https://doi.org/10.10 80/00036846.2018.1470315.

Parshakov P., Zavertiaeva M. (2015), Success in eSports: Does Country Matter?, DOI: https://doi. org/10.13140/RG.2.1.3723.9445.

Pizzo A.D., Baker B.J., Na S., Lee M.A., Kim D., Funk D.C. (2018), eSport vs. Sport: A Comparison of Spectator Motives, "Sport Marketing Quarterly", No. 27(2), pp.108-123.

Prat A. (2002), Should a team be homogeneous?, "European Economic Review", No. 46(7), pp. 1187-1207, DOI: https://doi.org/10.1016/S0014-2921(01)00165-9.

Semenov A., Romov P., Korolev S., Yashkov D., Neklyudov K. (2016), Performance of machine learning algorithms in predicting game outcome from drafts in Dota 2, [in:] International Conference on Analysis of Images, Social Networks and Texts, Cham, pp. 26-27, DOI: https://doi. org/10.1007/978-3-319-52920-2_3.

Statista (2019), https://www.statista.com/statistics/748044/number-video-gamers-world/ [access on: 20.06.2019].

Stępnik A. (2009), E-sport z perspektywy teorii sportu, "Homo ludens", No. 1(1), pp. 213-222.

Suits B. (2007), The elements of sport, "Ethics in sport", No. 2, pp. 9-19.

Verhoeff, G. (2019), Professionalization of eSports Broadcasts. The Mediatization of Dream Hack Counter-Strike Tournaments, [in:] eSports Yearbook 2017/18, edit. J. Hiltscher, T.M. Scholz, https://esportsyearbook.com/eyb201718.pdf [access on: 25.06.2019].

Wagner M.G. (2006), On the Scientific Relevance of eSports, [in:] International conference on internet computing, pp. 437-442. 
Abstract: The presented text addresses the issue of the influence of national diversity of eSports teams on their effectiveness in winning DOTA 2 games. The analyses were based on data concerning the entire population of teams participating in The International series tournaments. The results of the analyses confirm the hypothesis that teams with a strong national diversity, more often than teams with a high national homogeneity, achieve a high effectiveness coefficient and occupy a high place in the final classification of the analyzed tournaments.

Keywords: national diversity, eSport, eSports teams effectiveness, DOTA 2, eSports team diversity

Article submitted: 6.07.2019; article accepted: 21.10.2019. 